\title{
Identidade cultural e reconhecimento: tensões entre a política ambiental e as populações tradicionais
}

\author{
Identidad cultural y reconocimiento: tensiones entre la política \\ ambiental y las poblaciones tradicionales
}

\section{Cultural identity and recognition: tensions between the environmental policy and traditional populations}

\author{
Mara Rúbia Muniz Monteiro \\ monteiro.mrm@gmail.com \\ Doutoranda do PPG em Sociologia da UFPR
}

Resumo: Este trabalho aborda as contradições dos dispositivos legais que respaldam as políticas ambientais concernentes à criação de Unidades de Conservação de Proteção Integral, cuja ênfase está nas manifestações de diferentes conflitos de resistência em face da sobreposição de direitos. Está contextualizado a partir da criação de Unidades de Conservação na Amazônia, especificamente a criação do Parque Estadual Rio Negro (Amazonas). Caracterizado como área de proteção integral, localiza-se em território ocupado por comunidades tradicionais, dentre as quais povos indígenas, que presenciam o declínio de seus direitos garantidos constitucionalmente. Revelamse as contradições entre as realidades plurais e as políticas ambientais.

Palavras-chave: Pluralidade cultural. Comunidades tradicionais. Direitos. Políticas públicas.

Resumen: Este artículo aborda las contradicciones de las disposiciones legales que aseguran las políticas ambientales políticas ambientales relativas a la creación de Unidades de Conservación y Protección Integral, cuyo énfasis está en las manifestaciones de los diferentes conflictos de resistencia contra la superposición de derechos. Lo que se contextualiza con la creación de Unidades de Conservación en la Amazonia, específicamente la creación del Parque Estatal de Río Negro (Amazonas), caracterizado como área de protección integral, situado en territorio ocupado por poblaciones tradicionales, que están perdiendo sus derechos garantizados por la Constitución, revelando las contradicciones entre las realidades plurales y las políticas ambientales.

Palabras-Clave: Pluralidad cultural. Comunidades tradicionales. Derechos. Políticas públicas.

Abstract: This paper discusses the inconsistencies in the legal instruments that support the environmental policies concerning the creation of Integral Protection Conservation Units that emphasize the manifestation of different conflicts of resistance due to the overlap of rights. It focus on the creation of the Integral Protection Conservation Units in the Amazon, in particular the creation of the Rio Negro State Park (Amazonas State). It is an integral protection unit situated within an area occupied by traditional communities. This includes indigenous people that witness their constitutional rights 
decline. Thus, it reveals the discrepancies between plural realities and environmental policies.

Keywords: Cultural plurality. Traditional communities. Rights. Public policy.

\section{INTRODUÇÃO}

O presente tema nasce da inquietação concernente ao reconhecimento das relações simbólicas, construídas a partir da relação homem/natureza, manifestadas no universo dos saberes e práticas tradicionais, ora ameaçados pela implantação de políticas públicas ambientais relativas à criação de Unidades de Conservação de Proteção Integral. Ao considerar a amplitude e complexidade do tema, importa saber, na especificidade do contexto dos povos e das comunidades tradicionais da Amazônia, sobre a capacidade, ou não, dessas políticas alcançarem suas realidades plurais concretas. Problemática que envolve a existência de uma ordem expressa em dispositivos jurídicos que devem responder às necessidades que envolvem o reconhecimento das identidades constitutivas destas populações, caracterizadas como portadores de identidade étnica e coletiva, garantida normativamente.

Tanto nacional como internacionalmente, encontram-se, justamente, tais dispositivos, voltados para a problemática do reconhecimento, de sua efetividade factual, já que os valores tradicionais construídos historicamente são compreendidos no nível da proteção do direito. Entretanto, observa-se uma fragilidade, uma linha tênue entre as garantias jurídicas e as políticas públicas.

Neste sentido, questiona-se como se dá a articulação entre a política e a ordem jurídica no contexto da relação entre sociedade e meio ambiente em face do reconhecimento da identidade, tendo em vista as assimetrias existentes entre a fala das tradições, secularmente presentes, e a letra da lei. A despeito das contradições, é importante destacar quais leis foram justamente instituídas com o objetivo de dar resposta às lutas sociais em prol do reconhecimento da identidade. De onde se parte para indagar acerca da discrepância entre reconhecer e negar direitos.

Trata-se, mais especificamente, das contradições sublinhadas entre dispositivos legais que respaldam as políticas concernentes à criação de Unidades de Conservação de Proteção Integral e a noção de sujeito de direito articulada em face da autodeterminação de povos e comunidades tradicionais, no sentido de portabilidade de uma identidade étnica e coletiva. Cenário em que se expressam diferentes conflitos de resistência em face da sobreposição dos direitos ambientais em relação aos direitos culturais que envolvem os bens de natureza material e imaterial. Sendo este, pois, o caso concreto da criação de Unidades de Conservação de Proteção Integral na Amazônia, como a criação em 1995 do Parque Estadual Rio Negro, no Estado do Amazonas, região norte do Brasil, localizado em área ocupada por povos indígenas e comunidades tradicionais. 


\section{AS RELAÇÕES SUJEITO-MUNDO E A VALIDADE NORMATIVA}

Os universos simbólicos construídos por diferentes grupos sociais, em cada caso, servem de orientação para descrever internamente os aspectos correspondentes às suas práticas e saberes reconhecidos intersubjetivamente, e que devem ser observados no âmbito da norma jurídica. Trata-se, mais especificamente, das imagens de mundo dos sujeitos que, como tal, são constitutivas dos seus sistemas de conhecimento. Perspectiva esta que deve ser considerada quando na proposição de normas externas que se pretendem válidas.

A problemática está no abismo entre os diferentes significados de mundo construídos pelos sujeitos e o que o direito prescreve, criando um vazio do conteúdo valorativo referenciados à própria autenticidade das imagens de mundo construídas por esses sujeitos. Este abismo pode ser traduzido, no campo prático, a partir do seguinte entendimento descrito por Shiraishi Neto:

Nas últimas décadas, diversos povos e grupos sociais portadores de identidade coletiva e étnica, organizados em movimentos sociais, vem buscando garantir e reivindicar direitos, que sempre lhes foram negados pelo Estado (...). O Estado brasileiro tem negado sistematicamente a existência social desses grupos, na medida em que as políticas públicas são pensadas de forma 'universal', levando à constituição do 'reino de um direito único', que mais tem servido para 'apagar' as diferenças existentes do que para garantir o direito às diferenças. (SHIRAISHI NETO, 2005, p. 1).

A relação entre a construção do saber enraizado na tradição cultural e a normatividade não pode prescindir de uma concepção abstrata de sujeito e de mundo. Como expõe Castro (2002), neste universo de produção do conhecimento existem múltiplas dimensões, estando estas além dos elementos técnicos, pois incorporam as diferentes expressões simbólicas dos sujeitos que organizam o seu modus vivendi. Certamente, a restrição às práticas socioculturais de determinadas comunidades de cultura deve ser, pois determinações e restrições relativas ao uso da terra e dos recursos naturais que podem interferir diretamente na forma de organização de seu modus vivendi. Quadro que reflete a inconsistência entre a aplicabilidade e efetividade da norma jurídica e a realidade plural de diferentes comunidades de cultura.

No caso brasileiro, é pertinente reafirmar que a Constituição Federal confere proteção às manifestações culturais de diferentes grupos sociais e étnicos. Entretanto, a colisão entre a reprodução da identidade destes grupos e a regulamentação do direito ambiental é interpretada como um dos principais motivos dos conflitos quanto à sobreposição de direitos. Ora, a experiência e os conhecimentos tradicionais possuem uma relação estreita com as formas de uso da terra e dos recursos naturais e, portanto, devem ser analisados observando, em cada caso, os saberes e práticas culturalmente construídos.

A reprodução da identidade cultural, constitutiva das imagens de mundo dos sujeitos, que compõe este quadro de sobreposição de direitos, deve ser objeto de discussão no âmbito da gestão conjunta entre as instâncias de poder, competentes quanto à 
aplicação das normas, e as comunidades ora afetadas diretamente pelas políticas públicas que incidem diretamente em seu modus vivendi. Sendo, pois, um cenário marcado por alteridades múltiplas, onde o arcabouço jurídico deve dialogar com as especificidades de realidades bastante plurais, considerando esse universo complexo e multifacetado das imagens de mundo construídas por diferentes grupos sociais.

\section{DA INVISIBILIDADE DAS POPULAÇÕES TRADICIONAIS AO MARCO REGULATÓRIO DA IDENTIDADE}

Os povos e comunidades tradicionais da região amazônica são marcados por um longo processo histórico de invisibilidade frente às políticas públicas que deveriam garantir a manutenção dos bens materiais e imateriais. No centro desta problemática reside um contexto político marcado por interesses divergentes acerca da regulamentação de terras tradicionalmente ocupadas. Assegurar o território destas populações em face de suas práticas socioculturais, portanto, passou a ser alvo de diferentes mobilizações.

Seguindo a linha interpretativa de Almeida (2004), considera-se que a territorialidade é um dos fatores de identificação, marcada por um sentimento de pertencimento ao espaço. Este fator de identificação é o aspecto essencial que caracteriza a ideia de uma 'população tradicional', que possui uma estreita relação com o uso da terra e dos recursos naturais. Entretanto, a ameaça ao seu modus vivendi é constante.

Certamente, desde a promulgação da Constituição de 1988, a realidade sociocultural e ambiental da região amazônica passou a ser interpretada por novos olhares em face da proteção jurídica dos bens materiais e imateriais. Neste cenário, diferentes mobilizações sociais surgiram com o intuito de pleitear a proteção dos interesses coletivos dos povos e comunidades tradicionais. Um movimento necessário frente ao descaso das instâncias de poder público, que ainda mantém seus interesses políticos articulados aos interesses econômicos do mercado.

O direito territorial tem um avanço significativo, passando a alcançar além dos indígenas e dos quilombolas, outras populações tradicionais. Realidade assegurada pela Política Nacional de Desenvolvimento Sustentável dos Povos e Comunidades Tradicionais, instituída pelo Decreto $n^{\circ}$ 6.040/07, segundo o qual:

Art. 3o Para os fins deste Decreto e do seu Anexo compreende-se por: I - Povos e Comunidades Tradicionais: grupos culturalmente diferenciados e que se reconhecem como tais, que possuem formas próprias de organização social, que ocupam e usam territórios e recursos naturais como condição para sua reprodução cultural, social, religiosa, ancestral e econômica, utilizando conhecimentos, inovações e práticas gerados e transmitidos pela tradição; II - Territórios Tradicionais: os espaços necessários à reprodução cultural, social e econômica dos povos e comunidades tradicionais, sejam eles utilizados de forma permanente ou temporária, observado, no que diz respeito aos povos indígenas e quilombolas, respectivamente, o que dispõem os artigos 231 da Constituição e 68 do Ato das Disposições Constitucionais Transitórias e demais 
regulamentações; e III - Desenvolvimento Sustentável: o uso equilibrado dos recursos naturais, voltado para a melhoria da qualidade de vida da presente geração, garantindo as mesmas possibilidades para as gerações futuras. (BRASIL, 2007).

Os povos e comunidades tradicionais passam, então, a ser reconhecidos como grupos culturalmente diferenciados, que apresentam formas singulares de uso dos territórios tradicionalmente ocupados:

As populações tradicionais são também definidas pela sua ligação de relativa simbiose com a natureza, pelo conhecimento aprofundado da natureza e de seus ciclos e pela noção de território ou espaço onde se reproduzem econômica e socialmente. (SANTILLI, 2005, p. 129).

Condições que reverberam no contexto de construção de sua identidade étnica e coletiva. O que é ratificado no objetivo da Política Nacional de Desenvolvimento Sustentável dos Povos e Comunidades Tradicionais, expresso em seu Art. $2^{\circ}$ :

Promover o desenvolvimento sustentável dos Povos e Comunidades Tradicionais, com ênfase no reconhecimento, fortalecimento e garantia dos seus direitos territoriais, sociais, ambientais, econômicos e culturais, com respeito e valorização à sua identidade, suas formas de organização e suas instituições. (BRASIL, 2007).

Observe-se que tais garantias jurídicas alcançam as populações tradicionais não indígenas e não quilombolas. Entretanto, vale destacar que embora exista uma legislação específica relativa aos direitos de populações tradicionais indígenas e quilombolas, ainda existe uma necessidade de especificações regulatórias para uma ampla categoria de segmentos sociais que incluem a denominação populações tradicionais. Como bem expõe Santilli:

A nova visão socioambiental considera que o Brasil possui enorme diversidade cultural, vivendo aqui povos indígenas, pescadores artesanais, extrativistas, ribeirinhos, etc., que desenvolvem relações próprias e diferenciadas com a natureza, tanto no plano simbólico quanto no campo das técnicas e modos de fazer e produzir [...]. (SANTILLI, 2005, p. 130).

São populações tradicionais que apresentam diferentes modos de vida. Ou, como diz Diegues (1996, p. 142), estas “[...] apresentam um conhecimento profundo dos recursos naturais, considerados como grupos diferenciados culturalmente, com seus respectivos e singulares processos de reprodução histórica."

Neste sentido, destaca-se a importância em considerar de forma acurada as características sociais, culturais, econômicas e ambientais constitutivas do modus vivendi singular dos povos e comunidades tradicionais em sua singularidade. De tal modo a garantir o disposto na Política Nacional de Desenvolvimento Sustentável de Povos e Comunidades Tradicionais, art. $1^{\circ}$, Inciso XIV: a preservação dos direitos culturais, o exercício de práticas comunitárias, a memória cultural e a identidade destas populações. 
A questão da insuficiência de especificações regulatórias de diferentes segmentos que estão inseridos nesta concepção de 'tradicionais' é relevante na medida em que há na região amazônica uma incidência recorrente de conflitos em virtude, sobretudo, da regulamentação fundiária. Destarte constituir um avanço o reconhecimento às diferenças sociais e culturais prescritos em lei, no sentido de garantir que estas populações possam viver de acordo com seus padrões de valores culturais e sociais construídos historicamente, é necessário aprofundar as análises acerca da insuficiência de especificações regulatórias relativas ao termo povos e comunidades tradicionais, pois que implicam nas questões relativas à territorialidade, ao espaço onde tais populações mantêm seus saberes e práticas - constituídas nas formas de uso da terra que ocupam tradicionalmente.

Sendo estes, pois, critérios relevantes quando se analisa a legislação pertinente aos direitos de território reivindicado por estas populações em face da sobreposição de direitos. Em que deve ser observado:

Art. $1^{\circ}$ As ações e atividades voltadas para o alcance dos objetivos da Política Nacional de Desenvolvimento Sustentável dos Povos e Comunidades Tradicionais deverão ocorrer de forma intersetorial, integrada, coordenada, sistemática e observar os seguintes princípios: [...] V - o desenvolvimento sustentável como promoção da melhoria da qualidade de vida dos povos e comunidades tradicionais nas gerações atuais, garantindo as mesmas possibilidades para as gerações futuras e respeitando os seus modos de vida e as suas tradições; VI - a pluralidade socioambiental, econômica e cultural das comunidades e dos povos tradicionais que interagem nos diferentes biomas e ecossistemas, sejam em áreas rurais ou urbanas; VII - a promoção da descentralização e transversalidade das ações e da ampla participação da sociedade civil na elaboração, monitoramento e execução desta Política a ser implementada pelas instâncias governamentais;[...] X - a promoção dos meios necessários para a efetiva participação dos Povos e Comunidades Tradicionais nas instâncias de controle social e nos processos decisórios relacionados aos seus direitos e interesses;[...] XII - a contribuição para a formação de uma sensibilização coletiva por parte dos órgãos públicos sobre a importância dos direitos humanos, econômicos, sociais, culturais, ambientais e do controle social para a garantia dos direitos dos povos e comunidades tradicionais. (BRASIL, 2007).

Embora os povos e as comunidades tradicionais da Amazônia tenham saído da invisibilidade, a sua realidade sociocultural e ambiental deve ser mantida sob os holofotes. Este mundo tão plural ainda é palco de diferentes conflitos. Dentre os quais, o declínio dos direitos destas populações, a ausência de sua participação nos processos decisórios, o não reconhecimento de sua identidade, e sua relação com a terra.

\section{SOBREPOSIÇÃO DAS UNIDADES DE CONSERVAÇÃO}

O Sistema Nacional de Unidades de Conservação da Natureza (SNUC), instituído pela Lei n. 9.985/00, estabelece os critérios e as normas para criação, implantação e gestão 
das unidades de conservação. Sendo considerado um marco importante de regulamentação do direito ambiental. O que é devido, sobretudo, à pressão exercida pela sociedade civil:

A criação de um sistema nacional de unidades de conservação, por meio de um conjunto articulado e representativo de amostras de ecossistemas brasileiros, com diferentes categorias de unidades de conservação, só passou a ser cogitada a partir do final dos anos 70, sob a influência de organizações ambientalistas internacionais. As unidades de conservação brasileiras eram até então criadas de forma esporádica, casuística e assistemática, de acordo com as oportunidades surgidas em contextos e circunstâncias políticas específicas. (SANTILLI, 2005, p. 110).

Em seu texto, a Lei n. 9.985/00 dispõe sobre a seguinte definição de unidade de conservação:

Art. 2o-Para os fins previstos nesta Lei, entende-se por: I - unidade de conservação: espaço territorial e seus recursos ambientais, incluindo as águas jurisdicionais, com características naturais relevantes, legalmente instituído pelo Poder Público, com objetivos de conservação e limites definidos, sob regime especial de administração, ao qual se aplicam garantias adequadas de proteção. (BRASIL, 2000).

No que concerne ao critério de conservação, a referida Lei dispõe o seguinte entendimento:

Art. 2o-Para os fins previstos nesta Lei, entende-se por: [...] II - conservação da natureza: o manejo do uso humano da natureza, compreendendo a preservação, a manutenção, a utilização sustentável, a restauração e a recuperação do ambiente natural, para que possa produzir o maior benefício, em bases sustentáveis, às atuais gerações, mantendo seu potencial de satisfazer as necessidades e aspirações das gerações futuras, e garantindo a sobrevivência dos seres vivos em geral. (BRASIL, 2000).

Sobre os grupos específicos que compreendem as unidades de conservação, têm-se as Unidades de Proteção Integral e as Unidades de Uso Sustentável. As Unidades de Proteção Integral tem por objetivo (Art. $7^{\circ}, \S 1^{\circ}$ ): a preservação da natureza, sendo admitido o uso indireto dos recursos naturais; enquanto que as Unidades de Uso Sustentável tem por objetivo (Art. $7^{\circ}, \S 1$ ㅇ): a compatibilização da conservação da natureza em relação ao uso sustentável de parcela dos seus recursos naturais. Segue disso as seguintes categorias de Unidade de Conservação (a) de Proteção Integral (Art. $8^{\circ}$, Incisos I, II, III, IV, V): Estação Ecológica; Reserva Biológica; Parque Nacional; Monumento Natural; Refúgio de Vida Silvestre; (b) de Uso Sustentável (Art. 14', Incisos I, II, III, IV, V, VI, VII): Área de Proteção Ambiental; Área de Relevante Interesse Ecológico; Floresta Nacional; Reserva Extrativista; Reserva de Fauna; Reserva de Desenvolvimento Sustentável; e Reserva Particular do Patrimônio Natural.

Posto isto, ressalte-se que:

A Lei SNUC reconhece, em diversos dispositivos, o papel e a contribuição das populações tradicionais para a conservação e o uso sustentável da diversidade biológica, 
tendo criado duas categorias de unidades de conservação de uso sustentável, especificamente destinadas a abrigar as populações tradicionais e proteger os meios de vida e a cultura dessas populações. Além das referidas unidades de conservação, que têm por objetivo principal abrigar populações tradicionais e proteger os meios de vida e a cultura dessas populações, as florestas nacionais também admitem a presença de populações tradicionais residentes. Embora o objetivo primordial das florestas nacionais não seja abrigar populações tradicionais, e sim promover o uso múltiplo sustentável dos recursos florestais, a permanência de populações tradicionais que as habitam quando de sua criação é expressamente admitida. (SANTILLI, 2005, p. 125).

Em face do teor que contempla a definição conferida ao termo conservação, seguido da definição das Unidades de Conservação de Proteção Integral e de Uso Sustentável, para os fins da análise que seguem neste artigo, expõem-se o seguinte objetivo específico da Política Nacional de Desenvolvimento Sustentável de Povos e Comunidades Tradicionais (Art. $3^{\circ}$, Inciso II):

[..] solucionar e/ou minimizar os conflitos gerados pela implantação de Unidades de Conservação de Proteção Integral em territórios tradicionais e estimular a criação de Unidades de Conservação de Uso Sustentável". Entretanto, o que se observa é a incidência recorrente de conflitos oriundos da criação de Unidades de Conservação de Proteção Integral em áreas habitadas por estas populações, e que acabam sofrendo com as expropriações, com os processos de restrições às suas práticas sociais. (BRASIL, 2007).

Este texto disposto na Política Nacional de Desenvolvimento Sustentável de Povos e Comunidades Tradicionais já vem resguardar a possibilidade real de conflitos oriundos da implantação de Unidades de Conservação de Proteção Integral, quando da sobreposição de territórios ocupados por povos e comunidades tradicionais. Realidade esta recorrente na região amazônica, que envolve conflitos por vezes violentos em face da sobreposição de Unidades de Conservação de Proteção Integral em espaços habitados por populações tradicionais. (DIEGUES, 2000).

Embora o SNUC disponha em seu texto, dentro das categorias de Reservas Extrativistas (RESEX) e Reservas de Desenvolvimento Sustentável (RDS), especificamente, direitos relativos às populações tradicionais, a questão reside na decisão do poder público em instituir uma Unidade de Proteção Integral em territórios ocupados por estas populações. O que ocorre, em muitos casos, é que a possibilidade de expropriação, de restrição de práticas socioculturais, vem sendo questionada por estas populações na medida em que este tipo de ação interfere diretamente em seu modus vivendi, na sua identidade. Sobre isso, é importante ressaltar o seguinte entendimento de Santilli (2005):

O princípio fundamental que deve orientar toda a aplicação e interpretação judicial do SNUC é de que se trata de um sistema de unidades de conservação socioambientais que visa proteger e conservar os recursos naturais e culturais associados, baseado na compreensão unitária e indissociável de ambiente e cultura, e de integração entre o homem e a natureza. [...]. Tanto a diversidade biológica quanto a diversidade cultural 
são valores constitucionalmente protegidos, e a especial preocupação do legislador em assegurar às populações tradicionais as condições necessárias à sua reprodução física e cultural é motivada pelo reconhecimento de sua relação diferenciada com a natureza. (SANTILLI, 2005, p. 133-134).

Por ter a região amazônica um conjunto complexo de áreas com biodiversidade significativa, ocupadas por povos e comunidades tradicionais, a indissociável relação entre meio ambiente e cultura deve ser avaliada mais criticamente:

As unidades de conservação frequentemente abrigam populações tradicionais, mas a exiguidade de espaços coloca uma dicotomia entre as defesas dos direitos das populações tradicionais e o estabelecimento de unidades de conservação de proteção integral. Esses esforços não deveriam ser excludentes, mas o conflito revela preconceitos de ambos os lados e instaura uma oposição falaciosa. (VIANNA, 2008, p. 309).

Neste cenário, o que está em jogo é a possibilidade de declínio de direitos garantidos às populações tradicionais. O problema, conforme expressa Vianna, é que:

[...] o poder público não tem uma política definida para enfrentar a sobreposição de territórios com finalidades diferentes [...] é necessário ultrapassar as incongruências legais e assumir que a sobreposição dos territórios destinados à conservação da biodiversidade e/ou à proteção da biodiversidade, por si só, implica uma discussão sobre seu destino e sobre seu gerenciamento. (VIANNA, 2008, p. 309).

Uma alternativa a este conflito seria a possibilidade de reclassificação das Unidades de Conservação de Proteção Integral que, em cada caso, poderiam ser transformadas em Reservas Extrativistas ou Reservas de Desenvolvimento Sustentável. Entretanto, esta solução "[...] foi excluída da Lei SNUC - apesar de aprovada pelo Congresso Nacional, foi vetada pelo presidente da República." (SANTILLI, 2005, p. 167). O que tem ocorrido é a criação de Reservas Extrativistas ou Reservas de Desenvolvimento Sustentável localizadas em outras áreas, mas que não àquelas onde foram criadas as Unidades de Conservação de Proteção Integral em conflito. Medida que vem sendo contestada, em casos específicos, pelos povos e comunidades tradicionais afetados diretamente pela implantação destas unidades de conservação, sobretudo em razão das problemáticas resultantes das propostas de reassentamento.

\section{OS CONFLITOS NO PARQUE ESTADUAL RIO NEGRO}

O Parque Estadual do Rio Negro, criado pelo Decreto n. 16.497/95, está localizado nas áreas dos Municípios de Manaus, Novo Airão, Iranduba e Manacapuru, circundado pelas Áreas de Proteção Ambiental da Margem Esquerda e da Margem Direita do Rio Negro, sendo sua área inicial de aproximadamente de 257.422 ha no setor sul e de 178.620 ha no setor norte. Posteriormente, em 2001, a Lei n 2.646/01 veio a alterar os limites do Parque Estadual Rio Negro, Setores Norte e Sul, e das Áreas de Proteção Ambiental, das 
margens esquerda e direita do Rio Negro. A referida Unidade de Conservação de Proteção Integral é objeto de inúmeros conflitos socioambientais em razão da coexistência no interior do Parque, bem como no seu entorno, de populações tradicionais.

De acordo com o Instituto de Pesquisas Ecológicas (IPE, 2010), responsável pelo Plano de Gestão da Unidade de Conservação do Parque Estadual Rio Negro:

Diversos esforços têm sido empreendidos no sentido de prover melhor gestão desta área protegida (...) no entanto, a ausência de um documento de gestão, a falta de regularização fundiária, a inexistência de infraestrutura adequada que garanta o monitoramento, fiscalização e coerção às práticas que degradam esta Unidade, permitiram ao longo desses anos o agravamento dos problemas ambientais e sociais. (IPE, 2010, p. 15).

Neste contexto, certamente, a desinformação por parte das populações quanto às restrições de suas práticas deve ser considerada como um dos aspectos relevantes que demonstram o distanciamento entre as políticas públicas e a realidade local. Para o Instituto de Pesquisas Ecológicas (IPE, 2010, p. 26), “a criação da UC representou um ato autoritário do Estado, visto que não considerou os povos tradicionais que habitavam a região no momento de sua criação". Tal cenário de incertezas constitui o quadro de motivações das reivindicações destas populações, sobretudo, pela regularização de suas terras.

A questão fundiária é o principal objeto norteador dos conflitos decorrentes da criação do Parque:

[...] um dos maiores desafios para a gestão efetiva do PAREST Rio Negro Setor Sul é sua situação fundiária. [...]. Ao se criar esta UC, não se levou em consideração as perspectivas da população local e a sua gestão não foi implementada. Ações básicas, como a arrecadação da terra ao Instituto Nacional de Colonização e Reforma Agrária (INCRA), não foram realizadas [...]. (IPE, 2010, p. 20).

Apesar de ser uma Unidade de Proteção Integral, nela coexistem populações que se reconhecem como tradicionais, sejam estas indígenas ou pertencentes a outros segmentos sociais. Tais populações estão se deparando com problemas que envolvem a política de ordenamento territorial. (LIMA, 2013). Em que é notório o declínio de tais direitos.

Neste território constituído por diferentes grupos sociais, a possibilidade de reconhecimento de uma área como Terra Indígena no âmbito das discussões acerca da disposição das terras no qual o Parque está delimitado, emerge como uma motivação específica para que as comunidades ribeirinhas, que habitam o interior e o entorno do parque, se mobilizassem no sentido de reivindicarem seus direitos territoriais. A repercussão deste fato dá, então, ensejo, a criação em 2005 do Projeto de Desenvolvimento Sustentável (PDS) Cuieiras-Apuaú:

O PDS, porém, foi criado sem um trabalho mínimo de organização social mais extensivo, gerando uma situação de desinformação e conflito entre os assentados. Além disto, o assentamento está sobreposto à metade da área do PAREST Rio Negro Setor Sul, criando uma situação de contradição entre os objetivos das duas áreas: uma 
visando a proteção integral e outra propondo o assentamento humano mediante o desenvolvimento sustentável. Esta sobreposição cria uma situação de incertezas e indefinições quanto ao cenário fundiário da região, obrigando os órgãos envolvidos a negociar. (IPE, 2010, p. 20).

A situação que se alastra nas instâncias do poder público é a falta de diálogo com as populações afetadas, bem como, do diálogo interno entre diferentes setores do poder público, responsáveis pelas políticas relativas ao ordenamento territorial. O que vem agravar os conflitos.

A existência de comunidades e povos tradicionais, anterior à criação do Parque Estadual do Rio Negro Setor Sul, que dependem do território e dos recursos naturais, é o objeto em pauta discutido pelos representantes das populações localizadas dentro e no entorno do Parque. Como expõe Diegues:

[...] a permanência das populações tradicionais em áreas naturais protegidas não se justifica somente pela proteção e pelo reconhecimento da grande bagagem de etnoconhecimento transmitido de geração em geração a respeito das condições naturais, pela necessidade de garantir seus direitos históricos a seu território, mas também como exemplos a serem considerados pela civilização urbano-industrial na redefinição necessária de suas relações atuais com a natureza. (DIEGUES, 2000, p. 72).

No interior do Parque Estadual Rio Negro estão localizadas as comunidades às margens do Rio Cuieiras (Barreirinhas, Boa Esperança e Nova Esperança) e do Rio Negro (Jaraqui, Araras, Baixote e Caioé). Segundo o Instituto de Pesquisas Ecológicas, existem ainda outras comunidades que utilizam a área do Parque para desenvolver atividades produtivas. Segue disto, a inclusão de comunidades como as de Tatulândia, São João do Tupé e Agrovila, que foram incluídas nas análises do referido Instituto por estarem na área de fronteira do Parque, embora pertençam a Reserva de Desenvolvimento Sustentável do Tupé.

Nestas, há a presença de famílias indígenas e não indígenas, que nos anos de 1980, “[...] conformaram-se como comunidades e passaram a reivindicar alguns direitos e benefícios junto ao poder público, no que concerne à posse da terra e atendimento à educação e à saúde." (IPE, 2010, p. 95).

No final dos anos de 1990, as comunidades indígenas do Rio Cuieiras, de Nova Canaã, bem com as comunidades de Terra Preta e São Tomé, passaram a se mobilizar e atuar em conjunto com movimentos indígenas pela garantia de seus direitos territoriais, sendo a partir disto reconhecidas pela Fundação Nacional do índio (FUNAI) como populações indígenas. No que concerne às comunidades não indígenas, ainda de acordo com o Instituto de Pesquisas Ecológicas, no ano de 2000, estas se organizaram e passaram a reivindicar um assentamento junto ao INCRA. O que resultou na criação do Programa de Desenvolvimento Sustentável (PDS) Cuieiras-Apuaú.

Em relação às atividades econômicas e produtivas das famílias que vivem no interior e no entorno do parque existem distinções significativas. As comunidades que estão 
mais próximas da capital, Manaus, são mais populosas e mantém uma relação distinta com o espaço quando comparadas às comunidades que vivem no interior do Parque. No primeiro caso, em face do histórico de ocupação, a exploração da madeira tem destaque:

A maioria dos moradores da região do PAREST Rio Negro Setor Sul e entorno tem consciência de sua condição marginalizada dentro desta divisão do trabalho, bem como dos prejuízos sociais e ambientais resultantes da retirada indiscriminada de madeira. Muitos demonstram interesse em mudar a situação em que vivem, mas se veem sem alternativas para a obtenção dos meios necessários à sua subsistência. (IPE, 2010, p. 113).

No segundo caso, são evidenciadas com mais intensidade as atividades produtivas de subsistência e atividades econômicas de baixo impacto ambiental. Sobre isto, dispõe o documento do Instituto de Pesquisas Ecológicas:

As famílias mantêm a agricultura como forma de territorialização, identidade e produção, [...]. Um dos seus meios de subsistência é a roça, também chamada de coivara ou corte-e-queima, tendo a mandioca como base alimentar. Cerca de $20 \%$ das famílias produzem farinha como principal produto para a comercialização, evidenciando uma agricultura voltada para o suprimento das necessidades domésticas. Além disto, se utilizam de instrumentos manuais como terçados, machados, enxadas e motosserras (em alguns casos) durante o processo produtivo. O uso de agroquímicos é pouco frequente. Neste tipo de agricultura, os papéis de cada membro da família são bem definidos. Cabe aos homens adultos e aos jovens a realização dos processos de roçagem (broca), derrubada das árvores e queima. O plantio geralmente é realizado por toda a família. As mulheres e filhos mais novos são responsáveis pelo manejo das roças (limpeza e replantio) e colheita. (IPE, 2010, p. 108).

Destarte as distinções entre as atividades econômicas e produtivas destas populações, a questão que prevalece é a construção de sua identidade constituída a partir das relações que estabelecem com as formas de uso da terra e dos recursos naturais e, no caso específico das atividades de impacto ambiental considerável, a falta de alternativas para a subsistência das mesmas. Neste cenário, para Cunha (2012), a problemática concerne a questões de ordem jurídica referentes ao direito ambiental, territorial e cultural, bem como, conflitos entre os divergentes interesses do poder público, de Organizações Não Governamentais, das comunidades tradicionais e das federações indígenas.

Posto isto, destaca-se alguns pontos relevantes que constam no Plano de Gestão da Unidade de Conservação do Parque Rio Negro, realizado pelo Instituto de Pesquisas Ecológicas:

Falta de coerência na elaboração dos limites do Parque para a conservação dos ecossistemas (deve-se abranger toda uma bacia, ou hábitat); Desestruturação do modo de vida tradicional das comunidades; Falta de reconhecimento das territorialidades das comunidades (indígenas e não indígenas); A categoria Parque não se adequa à realidade local [...]. (IPE, 2010, p. 127). 
São adicionadas à este quadro as sobreposições relativas às propostas de destinações do território; a ausência de políticas públicas eficazes para o uso dos recursos naturais; a inabilidade das instâncias do poder público em dialogar com as comunidades; a falta de reconhecimento, por parte do poder público, do interesses e demandas das comunidades; a indefinição da situação fundiária; dentre outros.

\section{CONSIDERAÇÕES FINAIS}

Os processos de inclusão à luz do reconhecimento de identidades culturais plurais devem ser considerados como um dos aspectos de maior importância da ordem social, jurídica e política - na problemática que nela não se encerra, dentro da perspectiva do reconhecimento formal. Isto significa uma tensão permanente, pois se de um lado a lei é igual, do outro os sujeitos constituem diferenças a julgar pelas múltiplas realidades. $\mathrm{O}$ que coloca em tela o fato de que as demandas originadas pelos conflitos em face das Unidades de Conservação podem ser consideradas legítimas ao trazer como fundamento o reconhecimento e acolhimento de valores imprescindíveis e porque não dizer imprescritíveis.

Neste quadro, é pertinente considerar que as expressões valorativas dos povos e comunidades tradicionais são reveladas nas diferentes relações sujeito-mundo, na expressão da autenticidade de suas formas de vida, de seus saberes e práticas construídos historicamente e repassados por gerações.

Tanto a diversidade biológica quanto a diversidade cultural são garantidas constitucionalmente, e sua relação indissociável deve ser tomada como princípio norteador quando na criação de Unidades de Conservação. São necessários dados criteriosos que, de fato, possam descrever a realidade sociocultural e ambiental dos territórios em conflito.

A coexistência de populações tradicionais no espaço delimitado do referido Parque Estadual Rio Negro ratifica a desconsideração por parte das instâncias de poder das relações simbólicas construídas por essas populações neste território que secularmente habitam, mantendo com ele uma conexão indissociável entre natureza e cultura. O que vem reverberar em diferentes conflitos oriundos da sobreposição dos direitos ambientais em relação aos direitos culturais. Tendo, pois, como principal objeto de disputa a preservação de um modus vivendi ora ameaçado.

A questão repercute nos desafios contemporâneos a serem enfrentados em razão da identidade cultural destas populações, cujo choque entre a noção de pertença e o meio ambiente a ser preservado é o que está no cerne destes conflitos em torno da implantação do Parque Estadual Rio Negro. Um contexto que reflete os limites e tensões existentes entre o significado do mundo do sujeito e o que prescreve o direito em face de suas realidades concretas e plurais. 


\section{REFERENNCIAS}

ALMEIDA, Alfredo Wagner. Terras tradicionalmente ocupadas. Processos de territorialização e movimentos sociais. Revista Brasileira de Estudos Urbanos e Regionais, n. 1, maio 2004.

BRASIL. Decreto $\mathrm{n}^{\circ}$ 6.040, de 07 de Fevereiro de 2007. Institui a Política Nacional de Desenvolvimento Sustentável dos Povos e Comunidades Tradicionais. Diário Oficial da União, Brasília, 2007.

Lei no 9.985 de 18 de julho de 2000. Regulamenta o art. 225, § $1^{\circ}$, incisos I, II, III, e VII da Constituição Federal, institui o Sistema Nacional de Unidades de Conservação da Natureza e dá outras providências. Diário Oficial da União, Brasília, 2000.

DIEGUES, Antônio Carlos. O mito do paraíso desabitado. Revista do Patrimônio Histórico e Artístico Nacional, n. 24, p. 141-151, 1996.

DIEGUES, Antônio Carlos. O mito moderno da natureza intocada. São Paulo: HUCITEC, 2000.

IPE. Instituto de Pesquisas Ecológicas. Plano de Gestão Parque Estadual do Rio Negro Setor Sul. Versão para consulta pública. Manaus: IPE, 2010.

CASTRO, Edna. Território, Biodiversidade e Saberes de Populações Tradicionais. In: ; PINTON, Florence (Orgs.). Faces do trópico úmido: conceitos e questões sobre desenvolvimento e meio ambiente. Belém: CEJUP, 1997.

CUNHA, Manuela; ALMEIDA, Mauro. Enciclopédia da floresta. São Paulo: Companhia das Letras, 2002.

CUNHA, Elizabeth. Conflitos fundiários no Parque Estadual do Rio Negro Setor Sul. 2012. Dissertação (Mestrado) - Instituto Nacional de Pesquisas da Amazônia - INPA. Manaus, AM.

LIMA, Vilma et al. Ordenamento Territorial em Unidade de Conservação de Proteção Integral no Amazonas - Brasil. In: REENCUENTRO DE SABERES TERRITORIALES LATINO-AMERICANOS, 2013, Lima. Anais .... Lima: EGAL, 2013.

SANTILLI, Juliana. Socioambientalismo e novos direitos: proteção jurídica à diversidade biológica e cultural. São Paulo: Peirópolis, 2005.

SHIRAISHI NETO, Joaquim. "Crise" nos padrões jurídicos tradicionais: o direito em face dos grupos sociais portadores de identidade coletiva. In: XIV CONGRESSO NACIONAL DE PESQUISA EM PÓSGRADUAÇÃO EM DIREITO, 2005, Fortaleza. Anais .... Fortaleza: CONPEDI, 2005.

VIANNA, Lucila. De invisíveis a protagonistas: populações tradicionais e unidades de conservação. São Paulo: Annablume, 2008.

Recebido para avaliação em 01-05-2014

Aceito para Publicação em 04-12-2014 